\title{
Metabotropic glutamate receptors as novel therapeutic targets on visceral sensory pathways
}

\author{
L. Ashley Blackshaw' ${ }^{1,2,3}$, Amanda J. Page ${ }^{1,2,3}$ and Richard L. Young ${ }^{1,2}$ \\ 1 Nerve Gut Research Laboratory, Department of Gastroenterology and Hepatology, Hanson Institute, Royal Adelaide Hospital, Adelaide, SA, Australia \\ 2 Nerve Gut Research Laboratory, Discipline of Medicine, University of Adelaide, Adelaide, SA, Australia \\ ${ }^{3}$ Discipline of Physiology, School of Molecular and Biomedical Sciences, University of Adelaide, Adelaide, SA, Australia
}

\section{Edited by:}

James J. Galligan, Michigan State

University, USA

\section{Reviewed by:}

Klaus Bielefeldt, University of

Pittsburgh Medical Center, USA

James J. Galligan, Michigan State

University, USA

*Correspondence:

L. Ashley Blackshaw, Nerve Gut Research Laboratory, Level 1 Hanson Institute, Frome Road, Adelaide SA 5000, Australia.

e-mail: ashley.blackshaw@adelaide. edu.au
Metabotropic glutamate receptors ( $m G l u R$ ) have a diverse range of structures and molecular coupling mechanisms. There are eight mGluR subtypes divided into three major groups. Group I (mGluR1 and 5) is excitatory; groups II (mGluR2 and 3) and III (mGluR 4, 6, and 7) are inhibitory. All mGluR are found in the mammalian nervous system but some are absent from sensory neurons. The focus here is on mGluR in sensory pathways from the viscera, where they have been explored as therapeutic targets. Group I mGluR are activated by endogenous glutamate or constitutively active without agonist. Constitutive activity can be exploited by inverse agonists to reduce neuronal excitability without synaptic input. This is promising for reducing activation of nociceptive afferents and pain using mGluR5 negative allosteric modulators. Many inhibitory mGluR are also expressed in visceral afferents, many of which markedly reduce excitability. Their role in visceral pain remains to be determined, but they have shown promise in inhibition of the triggering of gastro-esophageal reflux, via an action on mechanosensory gastric afferents. The extent of reflux inhibition is limited, however, and may not reach a clinically useful level. On the other hand, negative modulation of mGluR5 has very potent actions on reflux inhibition, which has produced the most likely candidates so far as therapeutic drugs. These act probably outside the central nervous system, and may therefore provide a generous therapeutic window. There are many unanswered questions about mGluR along visceral afferent pathways, the answers to which may reveal many more therapeutic candidates.

Keywords: vagal afferents, gastro-esophageal reflux, lower esophageal sphincter, visceral pain

\section{INTRODUCTION}

Glutamate (Glu) is the major excitatory neurotransmitter in the central nervous system (CNS). It also acts to modulate synaptic transmission both pre- and post-synaptically. These actions are mediated via a large range of ionotropic (iGluR, NMDA, AMPA, and kainate), and metabotropic (mGluR, group I, II, III) receptors. iGluR are directly coupled to cation channels, and their activation evokes fast synaptic events which may lead to longer-term changes in excitability (Bleakman and Lodge, 1998; Yamakura and Shimoji, 1999). mGluR exist as eight subtypes of G-protein coupled receptor: Group I (mGluR1 and 5) are excitatory and are believed to act mainly via $\mathrm{G} \alpha \mathrm{q} /$ phospholipase C. Group II (mGluR2 and 3), and III (mGluR4, 6, 7, and 8) inhibit adenylate cyclase and alter cation

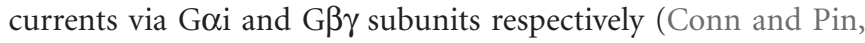
1997; Schoepp et al., 1999; Figure 1).

\footnotetext{
Abbreviations: AMPA, $\alpha$-amino-3-hydroxy-5-methyl-isoxazoleproprionate; CRD, colorectal distension; DRG, dorsal root ganglion; FD, functional dyspepsia; GABA, $\gamma$-amino butyric acid; GI, gastrointestinal; GORD, gastro-esophageal reflux disease; IBS, irritable bowel syndrome; IGLE, intraganglionic laminar endings; iGluR, ionotropic glutamate receptor; mGluR, metabotropic glutamate receptor; MPEP, 2-methyl-6-(phenylethynyl)-pyridine; MTEP, 3-[(2-methyl-1,3-thiazol-4-yl)ethynyl] pyridine; NCCP, non-cardiac chest pain; NMDA, $N$-methyl D-aspartate; NTS, nucleus tractus solitarius; TLESR, transient lower esophageal sphincter relaxation; TM, tension-mucosal; VMR, visceromotor response.
}

Thus the same transmitter may evoke fast excitation, slow excitation, slow inhibition, plus other cellular responses, often within the same group of CNS neurons. These actions underlie most, if not all major CNS functions, and GluR are the therapeutic targets of choice in a wide range of psychiatric and neurological diseases. As such there is great emphasis on CNS GluR in both academic and industrial research programs.

Our emphasis is on GluR in the peripheral nervous system (PNS). Because of the blood brain barrier, and the possibility to design drugs that may or may not cross it, GluR in the PNS clearly represent a range of targets distinct from CNS GluR. There is good evidence for involvement of GluR in the enteric nervous system (Liu and Kirchgessner, 2000; Foong and Bornstein, 2009), but our emphasis here is on GluR on sensory neurons that project to the CNS, which are well known to release glutamate from their central terminals (Millan, 1999; Bonham and Chen, 2002). These terminals are well established as targets for synaptic modulation by GluR, both in the spinal cord and brain stem. Therefore sensory neurons synthesize and release glutamate, and express GluR. We have demonstrated the existence of all iGluR and mGluR in the vagal sensory (nodose) ganglia, including neurons projecting to the stomach, with investigations in five species. If all 21 subtypes of these receptors were expressed on individual afferents innervating the gastrointestinal tract it would represent a complex regulatory system, with the possibility of parallel lines of peripheral control of 


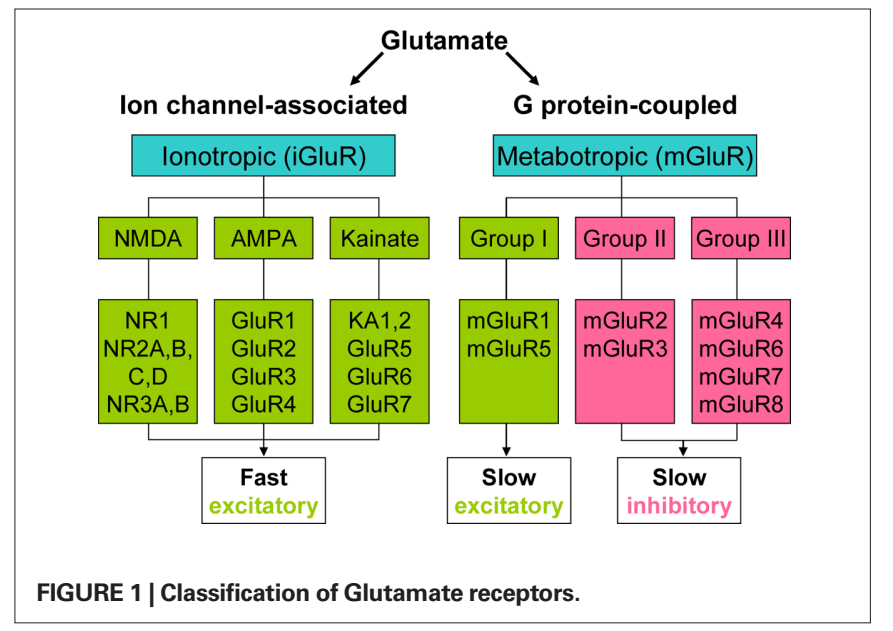

excitability and/or overlapping pathways that may interfere or even occlude one another. We do not yet know if there is expression of multiple GluR on individual afferents innervating the gastrointestinal tract and how their expression differs from the innervation of other tissues. What is often overlooked is that release of glutamate and expression of GluR is not confined to central terminals of sensory neurons.

\section{mGluR EFFECTS ON VAGAL AFFERENT PATHWAYS PERIPHERAL}

Expression of all eight mGluRs has been demonstrated in vagal afferent cell bodies of the nodose ganglia in several species (Hoang and Hay, 2001; Page et al., 2005), although we could not detect expression of mGluR3 and six mRNA in human and ferret nodose ganglia (Page et al., 2005). Immunohistochemistry, however revealed expression of all eight in ferret nodose ganglia. Functionally, vagal afferents from the upper gastrointestinal tract may be classified into three types, according to their mechanical sensitivity. Tension receptors respond only to distension and contraction of smooth or striated muscle; mucosal receptors respond only to mucosal stroking, and tension-mucosal receptors respond to both stimuli but are found so far only in ferret esophagus. Studies in mouse and ferret indicate that group II and III receptor agonists inhibit mechanical sensitivity of vagal gastro-esophageal afferents, whereas a group I agonist had no effect (Page et al., 2005). Ferret afferents were more effectively inhibited than mouse afferents, which may reflect greater expression and/or coupling of receptors; alternatively it may reflect the greater dynamic range of the afferents allowing inhibition to be more easily seen. A nonselective group III antagonist given alone increased mechanosensitivity of ferret afferents, indicating a role for endogenous glutamate causing ongoing activation via one or more classes of group III receptors on vagal afferents. We have since found more specific, as yet unpublished, evidence for a role of group III receptors in ongoing modulation. In the mGluR4 receptor knockout mouse, the sensitivity of mucosal receptors was increased in comparison to wild types. However, tension receptors were similar in knockouts and wild types, suggesting that mGluR4 may have a specific role. Neither of these classes of afferents was altered upon deletion of the mGluR8 gene (Figure 2).
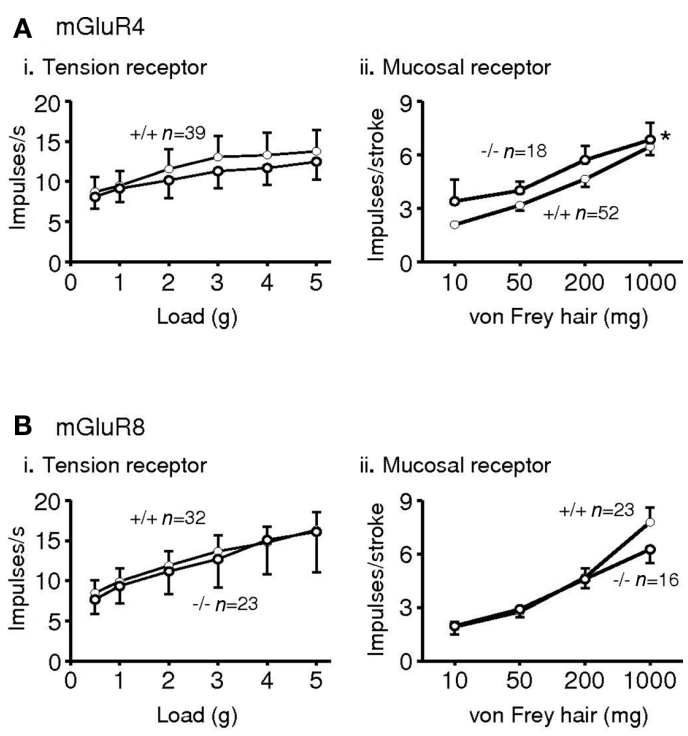

FIGURE 2 | Responses of gastro-esophageal vagal afferents to mechanical stimulation in mice deficient in mGluR4 ( $A^{*}$ ) or mGluR8 (B). (i) The effects of disrupting mGluR on the responses to circumferential tension (average impulses s${ }^{-1}$ over stimulus duration of $1 \mathrm{~min}$ ) of tension receptors. (ii) The effects of disrupting mGluR on the responses to mucosal stroking (impulses per stroke, mean of eight strokes) of mucosal receptors. The graphs show the mean \pm SEM. Significant differences between $\mathrm{mGluR}+/+(\bullet)$ and $-/-(\circ)$ mice (assessed using two-way ANOVA) is indicated adjacent to the response curves $\left({ }^{*} p<0.05\right) . n=$ number of afferents recorded. ${ }^{*}$ Previously presented. The metabotropic glutamate receptor mGluR4 is required for normal visceral mechanotransduction (Page et al., 2004).

Since the greatest effects of group III activation were seen in ferret afferents, it is perhaps not surprising that deleting one of these receptors at a time in mouse has unremarkable effects. No further studies of group III mGluR in mice were pursued. It may be important for group III mGluR to operate as heterodimers, as is seen with many other GPCR (Marshall, 2001), but evidence is lacking for direct associations between different group III mGluR. That they are co-expressed is highly likely, since our cell counts indicate there is considerable overlap of expression of different mGluR immunoreactivity within nodose neurons innervating the stomach, because most of them showed expression in $80-90 \%$ of cell bodies.

Metabotropic glutamate receptor 5 antagonists significantly reduce mechanosensitivity of gastro-esophageal vagal afferents in ferret and mouse (Slattery et al., 2006; Young et al., 2007), but not in guinea pig (Zagorodnyuk et al., 2003), indicating opposing excitatory and inhibitory roles for endogenous glutamate, and differences between species. The fact that a group I agonist was ineffective, yet an antagonist may cause inhibition, suggests that receptors are fully active under resting conditions. This may be due to glutamate released locally, or to constitutive activity, which is a notable feature of group I mGluR (Ango et al., 2001). The locally available glutamate would probably be released from the afferent endings themselves. In the case of tension receptors, these endings take the form of intraganglionic laminar endings (IGLE) in the stomach and esophagus (Zagorodnyuk and Brookes, 2000; Zagorodnyuk et al., 2001); IGLEs express the vesicular glutamate transporters VGLUT1 and VGLUT2 (Raab and Neuhuber, 2003, 2004; Ewald et al., 2006) 
and possess peripheral synaptic specializations (Neuhuber, 1987). These facts point strongly to an effector role for IGLEs in peripheral glutamatergic transmission. In view of evidence of mGluR5 expression in ferret gastric vagal afferents, peripheral transport of this receptor and inhibition of tension and TM receptor responses by 2-methyl-6-(phenylethynyl)-pyridine (MPEP), these findings support the notion that mechanical stimulation leads to endogenous glutamate release from gastro-esophageal IGLEs which in turn activates autoreceptors on tension and TM receptors, an effect that may be blocked by mGluR antagonists. Results from studies of gastro-esophageal vagal afferents in ferret in vivo confirmed earlier in vitro findings that an mGluR5 antagonist reduces mechanosensitivity of ferret tension receptors (Young et al., 2007). mGluR5 antagonism did not inhibit mucosal receptor mechanosensitivity in ferret, which may result if either mGluR5 were absent from this class of afferents in ferrets, or if mucosal receptors possessed mGluR5 that were inaccessible to endogenous glutamate released from IGLEs. In mouse mucosal afferents, however, an mGluR5 antagonist caused potent inhibition of mucosal afferents (Slattery et al., 2006), which could be attributable either to increased diffusion of glutamate through the mouse gut, or differences in receptor expression. Studies on mGluR1 on vagal afferents, which shares many features with mGluR5, are lacking, which represents a significant gap in the literature.

\section{CENTRAL}

Electrophysiological studies demonstrated that single neurons excited or inhibited by gastric distension can be identified throughout the ferret NTS (Young et al., 2007, 2008a). Intracerebroventricular MPEP acted rapidly and potently to inhibit a minority of NTS neurons that showed excitatory responses to gastric distension, however the majority of neurons tested with MPEP were only modestly attenuated or showed no effect. All neurons inhibited by gastric distension were unaffected by MPEP. These findings suggest that mGluR5 are functionally expressed only on excitatory pathways through the NTS and expression is restricted to a small subset of these. This finding contrasts with our earlier results with the GABA(B) receptor agonist baclofen, which reversibly inhibited all NTS neurons excited or inhibited by gastric distension (Partosoedarso et al., 2001). Our data on retrograde tracing of central terminals of gastric vagal afferents in ferrets showed that, like the rat (Shapiro and Miselis, 1985) and cat (Gwyn et al., 1979), ferret gastric vagal afferents terminate preferentially in the subnucleus gelatinosus in rostral regions of dorsal vagal complex with terminal fields extending into the dorsal mnNTS and fibers extending dorsomedially from the solitary tract (Young et al., 2007, 2008b). Combined with dual label immunohistochemistry these anatomical findings support a minor role for mGluR5 on a subset of second- or higher-order excitatory interneurons linked to gastric mechanoreceptor input. This was apparent due to (i) a lack of significant co-localization between mGluR5 immunoreactivity and retrogradely traced gastric vagal afferent terminal fields in the NTS, combined with (ii) high level mGluR5 expression in lateral regions of the mnNTS and solitary tract, and (iii) the absence of mGluR5 on DMV perikarya (Young et al., 2007). Additional support for this view is provided by the limited functional effect of central MPEP plus proof of presynaptic inhibition of gastric vagal input to the NTS by inhibitory Group II and III mGluR, but not by Group I mGluR (Glaum and Miller, 1993; Liu et al., 1998; Chen et al., 2002). Therefore, despite evidence of mGluR5 expression in the vagus in ferrets (Page et al., 2005) central mGluR5 seems unlikely to have a major functional role in vagal afferent terminals.

Labeling for mGluR4 and mGluR8 is abundant in gastric vagal afferents in the ferret nodose ganglion, at their termination site in the NTS (subnucleus gelatinosus) and in gastric vagal motorneurons, while labeling for mGluR6 and mGluR7 is weaker in these regions (Page et al., 2005; Young et al., 2008a). The mGluR8 agonist DCPG (i.c.v.) inhibited or markedly attenuated responses of most NTS neurons excited by gastric distension. The effects of DCPG were significantly reversed by the group III mGluR antagonist MAP4. In contrast, none of the NTS neurons inhibited by gastric distension were affected by DCPG. This indicates that group III mGluR are expressed in both peripheral and central vagal pathways, and that mGluR8 within the NTS selectively reduces excitatory transmission along gastric vagal pathways.

\section{mGluR EFFECTS ON SPINAL AFFERENT PATHWAYS}

Group I mGluR antagonists, particularly antagonists for mGluR5, have received a great deal of interest in their potential as analgesics for somatic pain and anxiolytics (Swanson et al., 2005). mGluR5 is expressed in various regions along the somatosensory pathway, including the dorsal horn of the spinal cord (laminae I and II) and pain-related CNS centers (Valerio et al., 1997; Neto et al., 2000; Tao et al., 2000). Selective mGluR5 antagonists, such as MPEP and MTEP, have been developed and these compounds have shown analgesic properties in several animal models of inflammatory and neuropathic somatic pain (Gasparini et al., 1999; Karim et al., 2001; Walker et al., 2001a,b; Fisher et al., 2002; Hudson et al., 2002; Cosford et al., 2003; Zhu et al., 2004; Varty et al., 2005).

\section{PERIPHERAL}

As in the nodose ganglia, there is evidence for expression of all $\mathrm{mGluR}$ in the dorsal root ganglia (DRG; Carlton and Hargett, 2007). Specific data on expression within DRG neurons innervating the gut are lacking, but functional evidence exists for some mGluR. It is unwise to extrapolate from observations in whole DRG to what is likely to be the case for visceral afferents. They make up a small proportion of DRG neurons - as little as $2 \%$ of the total. The majority of visceral DRG afferents are small-medium diameter peptidergic neurons (Tan et al., 2009), but even as such they may differ markedly from other phenotypically similar neurons (Brierley et al., 2008). Therefore there is much work yet to be done to determine the selectivity of expression of mGluR on visceral spinal afferents. There are several subtypes of visceral spinal afferents, which preferentially travel via the splanchnic (thoracolumbar) or pelvic (lumbosacral) innervation. The splanchnic nerves provide innervation of the abdominal viscera, whereas the pelvic nerve is restricted to pelvic organs, with overlap in the distal colon. Low threshold mucosal, muscular, and muscular-mucosal afferents are almost exclusive to the pelvic innervation and to the distal colon and rectum. High threshold serosal afferents are found in both pathways, and high threshold mesenteric afferents are carried exclusively in the splanchnic nerves. Mucosal, muscular, and muscular-mucosal receptors behave in a similar way 
to their vagal counterparts (mucosal, tension, and tension-mucosal). In those subtypes that are distension-sensitive, responses to distension are more likely to reach maximum at noxious levels than in vagal afferents, and some of these have been termed wide dynamic range afferents (Rong et al., 2004). Serosal and mesenteric afferents respond only at noxious levels of distension. (Brierley et al., 2008, 2009; Hughes et al., 2009).

Our preliminary data indicate no effect of group II or group III agonists on rat colonic afferents in an isolated preparation (Phillis and Blackshaw, unpublished). However, recent data indicate that group II mGluRs and TRPV1 receptors are co-expressed on peripheral nociceptors and activation of mGluRs can inhibit painful somatosensory transmission following TRPV1 activation. The data are consistent with group II and TRPV1 receptors being linked intracellularly by the cAMP/PKA pathway (Carlton et al., 2009).

Writhing behavior and c-fos expression in the spinal cord evoked by acetic acid are inhibited by MPEP (Bianchi et al., 2003; Zhu et al., 2004). However, administration of acetic acid into the peritoneal cavity is not regarded as a selective visceral stimulus since the peritoneum, a partly somatic structure, and probably other somatic structures, are involved in the responses observed (Martinez et al., 1999; Laird et al., 2001). We found that mGluR5 receptor antagonists inhibit the visceromotor (VMR) and autonomic responses to colorectal distension (CRD) in conscious rats. An action at peripheral sites mediating the analgesic effects was considered a possibility. This was tested by recording from two major populations of colonic mechanoreceptors - pelvic muscular and muscular/mucosal afferents, and splanchnic serosal afferents (Lindstrom et al., 2008). These studies demonstrated that MTEP was able to inhibit mechanosensitivity in both populations of afferents, corresponding to those responding at low and high threshold to distension in situ. This provides the first evidence for a peripheral site of action of mGluR5 antagonists contributing to the inhibition of the responses to CRD. It does not, however, rule out an additional action in the central nervous system, at either spinal or supraspinal sites. A study of mGluR5 in the bladder sensory pathway reached the opposite conclusion - that no effect of an antagonist could be seen on afferents in the isolated preparation, but inhibition of behavioral and reflex responses was readily observed in vivo (Hu et al., 2009). Therefore there may be different roles of mGluR5 in different visceral sensory pathways.

Inhibitory effects of MPEP on the VMR and the cardiovascular response to CRD indicate an involvement of mGluR5 in visceral sensory mechanisms, as previously suggested for somatic pain (Gasparini et al., 1999; Karim et al., 2001; Walker et al., 2001a,b; Fisher et al., 2002; Hudson et al., 2002; Cosford et al., 2003; Zhu et al., 2004; Varty et al., 2005). A peripheral site of action is perhaps not surprising since mGluR5 is strongly expressed in small diameter dorsal root ganglion neurons (Valerio et al., 1997; Walker et al., 2001b) and peripheral axons (Bhave et al., 2001; Walker et al., 2001b), although these studies did not discriminate between ganglion neurons innervating the colon and others. Nevertheless, several reports showed also a significant analgesic activity of peripheral mGluR5 in models of somatic pain (Bhave et al., 2001; Walker et al., 2001b).

Zhou et al. (2001) found that mGluR1 are present on peripheral cutaneous axons and their activation contributes to mechanical allodynia and inflammatory pain but not thermal hyperalgesia. No studies of this type are evident as yet on visceral afferents.

\section{CENTRAL}

Metabotropic glutamate receptor 5 antagonists appear to modulate somatic nociceptive processing at various levels of the nervous system in addition to peripheral afferent endings, including spinal dorsal horn and supraspinal sites (Dogrul et al., 2000; Neugebauer, 2002; Zhu et al., 2005), indicating that mGluR5 is involved in mediating or positively modulating pain. Central analgesic effects of mGluR5 antagonists have been extensively reported in different models, however contribution of mGluR5 in specific central regions has not been assessed in visceral pain. Since after peripheral administration the brain penetration of MPEP and MTEP is relatively high (Anderson et al., 2003) central sites of action mediating the analgesic effects on visceral pain in addition to peripheral sites are quite likely in our recent study (Lindstrom et al., 2008). Hu et al. (2009) recently demonstrated that ERK-mediated phosphorylation of Kv4.2 occurs downstream of mGluR5 activation in spinal cord dorsal horn neurons. Activation of group I mGluRs inhibited Kv4.2-mediated A-type K+ currents and increased neuronal excitability in dorsal horn neurons. These effects were mediated by activation of mGluR5, but not mGluR1.

There is good evidence that group II and group III mGluR at a supraspinal site may become induced in somatic inflammatory pain, but that they may be a poor clinical target for pain due to tolerance development and effects on other systems (Jones et al., 2005; Marabese et al., 2007). In this context, inhibitory mGluR may be recruited as an adaptive response to pain in a similar way to opiodergic pain control.

\section{mGIUR AS CLINICAL TARGETS GASTRO-ESOPHAGEAL REFLUX DISEASE}

One of our major findings with regard to a clinical indication for mGluR was that antagonism of mGluR5 potently inhibits the triggering of transient LES relaxations by a gastric load, and thereby reduces the number of reflux episodes. This suggests that mGluR5 antagonists may be novel and efficacious strategies in the management of gastro-esophageal reflux disease. This suggests that endogenous activation of mGluR5 is an important component of the pathway(s) triggering or regulating transient lower esophageal sphincter relaxation (TLESR). The close correlation between inhibition of reflux events and inhibition of TLESR by mGluR5 antagonists reconfirms that TLESR is the major mechanism of reflux in ferrets as it is in other species (Blackshaw et al., 1998; Frisby et al., 2005). Our ferret data are corroborated by studies in dogs which also show a potent and significant inhibitory effect of MPEP on TLESR (Jensen et al., 2005). We found on the other hand that an agonist of excitatory group I mGluR had the opposite effect to the antagonists by tending to stimulating TLESR, as would be expected, although the effects of agonists were inconsistent and not statistically significant. In contrast to effects of group I agonism, stimulation of the inhibitory group III mGluR reduced the triggering of TLESR. Group III agonists were, however, considerably less potent than group I (mGluR5) antagonists. A recent clinical trial indicated that the mGluR5 negative allosteric modulator ADX10059 reduced acid reflux which was associated with improvement in clinical symptoms in patients with reflux disease. ADX10059 therefore appears to have a potential role in the clinical management of reflux disease (Keywood et al., 2009). The proposed mechanism of action of mGluR on triggering of TLESR is shown schematically in Figure 3. 


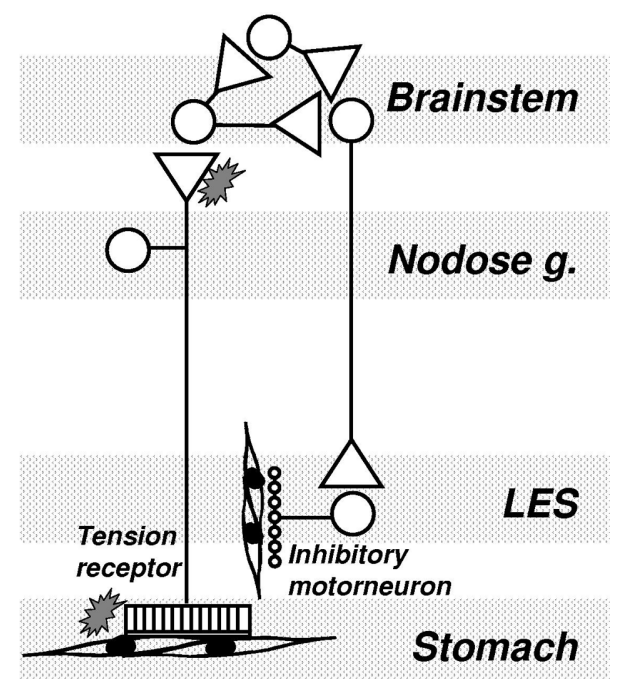

FIGURE 3 | Mechanism of mGluR action on transient lower esophageal sphincter relaxations (TLESR). Vagal tension receptors in the proximal stomach detect stretch of the wall by gastric content. They project into the brainstem where they synapse mainly on interneurons. A central program generator is triggered which probably comprises several inhibitory and excitatory neurons interacting pre- and post-synaptically. The output from the program generator is an episodic, powerful activation of vagal efferents projecting to the myenteric plexus of the LES. At this point they activate inhibitory intrinsic motorneurons which release inhibitory transmitter onto smooth muscle. mGluR may be found at several points throughout this circuit, both peripherally and centrally. Their role appears to be mainly presynaptic, and in some cases mainly peripheral (see text). Their role within the program generator and along vagal motor pathways is not known.

\section{REFERENCES}

Anderson, J. J, Bradbury, M. J., Giracello, D. R., Chapman, D. F., Holtz, G., Roppe, J., King, C., Cosford, N. D., and Varney, M. A. (2003). In vivo receptor occupancy of mGlu5 receptor antagonists using the novel radioligand $[3 \mathrm{H}] 3$ methoxy-5-(pyridin-2-ylethynyl) pyridine). Eur. J. Pharmacol. 473, 35-40.

Ango, F., Prezeau, L., Muller, T., Tu, J. C., Xiao, B., Worley, P. F., Pin, J. P., Bockaert, J., and Fagni, L. (2001). Agonist-independent activation of metabotropic glutamate receptors by the intracellular protein Homer. Nature 411, 962-965.

Bhave, G., Karim, F., Carlton, S. M., and Gereau, R.W.(2001). Peripheral group I metabotropic glutamate receptors modulate nociception in mice. Nat. Neurosci. 4, 417-423.

Bianchi, R., Rezzani, R., Borsani, E., and Rodella, L. (2003). mGlu5 receptor antagonist decreases Fos expression in spinal neurons after noxious visceral stimulation. Brain Res. 960, 263-266.

Blackshaw, L. A., Staunton, E., Dent, J., Holloway, R. H., and Malbert, C. H. (1998). Mechanisms of gastrooesophageal reflux in the ferret. Neurogastroenterol. Motil. 10, 49-56.
Bleakman, D., and Lodge, D. (1998). Neuropharmacology of AMPA and kainate receptors. Neuropharmacology 37, 1187-1204.

Bonham, A. C., and Chen, C. Y. (2002). Glutamatergic neural transmission in the nucleus tractus solitarius: $N$-methyl-D-aspartate receptors. Clin. Exp. Pharmacol. Physiol. 29, 497-502.

Brierley, S. M., Hughes, P. A., Page, A. J., Kwan, K.Y., Martin, C. M., O’Donnell, T.A., Cooper, N. J., Harrington, A. M., Adam, B., Liebregts, T., Holtmann, G., Corey, D. P., Rychkov, G. Y., and Blackshaw, L.A. (2009). The ion channel TRPA1 is required for normal mechanosensation and is modulated by algesic stimuli. Gastroenterology 137, 2084-2095. e2083.

Brierley, S. M., Page, A. J., Hughes, P. A., Adam, B., Liebregts, T., Cooper, N. J., Holtmann, G., Liedtke, W., and Blackshaw, L. A. (2008). Selective role for TRPV4 ion channels in visceral sensory pathways. Gastroenterology 134, 2059-2069.

Carlton, S. M., Du, J., and Zhou, S. (2009). Group II metabotropic glutamate receptor activation on peripheral nociceptors modulates TRPV1 function. Brain Res. 1248, 86-95.

\section{VISCERAL PAIN}

Visceral pain is a major clinical problem, mainly in the form of three major functional gastrointestinal disorders: irritable bowel syndrome (IBS), functional dyspepsia (FD), and non-cardiac chest pain (NCCP). They are associated with symptoms of unknown origin from the large intestine to the esophagus respectively. There is evidence for both peripheral and central sensory dysfunction in these conditions, in the absence of overt peripheral lesions or gross motor abnormalities. Most of the molecular targets so far pursued in clinical trials have been abandoned, mainly due to limited efficacy or adverse events unrelated to the disorder itself. Whether the answer lies in central or peripheral modulation of neural activity remains to be seen, but the high degree of convergence of sensory information in the spinal dorsal horn may suggest that other targets, such as either specific viscerosensory modulatory areas in the brain, or peripheral afferent endings hold the key. In comparison with reflux disease, the progress of mGluR as targets in visceral pain is slow, and there are no published clinical trials at the date of writing. Although there is better knowledge of the roles of mGluR in somatic pain pathways, the clinical situation is no different there. It is to be hoped that there will be a return on the investment of understanding the involvement of mGluR in pain pathways soon. In this regard mGluR5 appears one of the best candidates, and may therefore support more than one indication.

\section{ACKNOWLEDGMENT}

L. Ashley Blackshaw is supported by a National Health and Medical Research Council of Australia Principal Research Fellowship.

Carlton, S. M., and Hargett, G. L. (2007). Colocalization of metabotropic glutamate receptors in rat dorsal root ganglion cells. J. Comp. Neurol. 501, 780-789.

Chen, C. Y., Ling Eh, E. H., Horowitz, J. M., and Bonham, A. C. (2002). Synaptic transmission in nucleus tractus solitarius is depressed by Group II and III but not Group I presynaptic metabotropic glutamate receptors in rats. $J$. Physiol. 538, 773-786.

Conn, P. J., and Pin, J. P. (1997). Pharmacology and functions of metabotropic glutamate receptors. Annu. Rev. Pharmacol. Toxicol. 37, 205-237.

Cosford, N. D., Tehrani, L., Roppe, J., Schweiger, E., Smith, N. D., Anderson, J., Bristow, L., Brodkin, J., Jiang, X., McDonald, I., Rao, S., Washburn, M., and Varney, M. A. (2003). 3-[(2-Methyl-1,3-thiazol4-yl)ethynyl]-pyridine: a potent and highly selective metabotropic glutamate subtype 5 receptor antagonist with anxiolytic activity. J. Med. Chem. 46, 204-206.

Dogrul,A., Ossipov, M. H., Lai, J., Malan, T. P. Jr., and Porreca, F. (2000). Peripheral and spinal antihyperalgesic activity of SIB-1757, a metabotropic glutamate receptor (mGLUR(5)) antagonist, in experimental neuropathic pain in rats. Neurosci. Lett. 292, 115-118.

Ewald, P., Neuhuber, W. L., and Raab, M. (2006). Vesicular glutamate transporter 1 immunoreactivity in extrinsic and intrinsic innervation of the rat esophagus. Histochem. Cell Biol. 125, 377-395.

Fisher, K., Lefebvre, C., and Coderre, T. J. (2002). Antinociceptive effects following intrathecal pretreatment with selective metabotropic glutamate receptor compounds in a rat model of neuropathic pain. Pharmacol. Biochem. Behav. 73, 411-418.

Foong, J. P., and Bornstein, J. C. (2009). mGluR1 receptors contribute to nonpurinergic slow excitatory transmission to submucosal VIP neurons of guinea-pig ileum. Front. Ent. Neurosci. 13:46. doi: 10.3389/neuro.21.001.2009 Frisby, C. L., Mattsson, J. P., Jensen, J. M., Lehmann, A., Dent, J., and Blackshaw, L. A. (2005). Inhibition of transient lower esophageal sphincter relaxation and gastroesophageal reflux by metabotropic glutamate receptor ligands. Gastroenterology 129, 995-1004. Gasparini, F., Lingenhohl, K., Stoehr, N., Flor, P. J., Heinrich, M., Vranesic, I., Biollaz, M., Allgeier, H., Heckendorn, 
R., Urwyler, S., Varney, M. A., Johnson, E. C., Hess, S. D., Rao, S. P., Sacaan, A. I., Santori, E. M., Velicelebi, G., and Kuhn, R. (1999). 2-Methyl-6(phenylethynyl)-pyridine (MPEP), a potent, selective and systemically active mGlu5 receptor antagonist. Neuropharmacology 38, 1493-1503.

Glaum, S. R., and Miller, R. J. (1993). Metabotropic glutamate receptors depress afferent excitatory transmission in the rat nucleus tractus solitarii. J. Neurophysiol. 70, 2669-2672.

Gwyn, D. G., Leslie, R. A., and Hopkins, D. A. (1979). Gastric afferents to the nucleus of the solitary tract in the cat. Neurosci. Lett. 14, 13-17.

Hoang, C. J., and Hay, M. (2001). Expression of metabotropic glutamate receptors in nodose ganglia and the nucleus of the solitary tract. Am. J. Physiol. Heart Circ. Physiol. 281, H457-H462.

Hu, Y., Dong, L., Sun, B., Guillon, M. A., Burbach, L. R., Nunn, P. A., Liu, X., Vilenski, O., Ford, A. P., Zhong, Y., and Rong, W. (2009). The role of metabotropic glutamate receptor mGlu5 in control of micturition and bladder nociception. Neurosci. Lett.450, 12-17.

Hudson, L. J., Bevan, S., McNair, K., Gentry, C., Fox, A., Kuhn, R., and Winter, J. (2002). Metabotropic glutamate receptor 5 upregulation in A-fibers after spinal nerve injury: 2-methyl-6-(phenylethynyl)-pyridine (MPEP) reverses the induced thermal hyperalgesia. J. Neurosci. 22, 2660-2668.

Hughes, P. A., Brierley, S. M., Martin, C. M., Brookes, S. J., Linden, D. R., and Blackshaw, L. A. (2009). Postinflammatory colonic afferent sensitisation: different subtypes, different pathways and different time courses. Gut 58, 1333-1341.

Jensen, J., Lehmann, A., Uvebrant, A., Carlsson, A., Jerndal, G., Nilsson, K., Frisby, C., Blackshaw, L. A., and Mattsson, J. P. (2005). Transient lower esophageal sphincter relaxations in dogs are inhibited by a metabotropic glutamate receptor 5 antagonist. Eur. J. Pharmacol. 519, 154-157.

Jones, C. K., Eberle, E. L., Peters, S. C., Monn, J.A., and Shannon, H.E. (2005). Analgesic effects of the selective group II (mGlu2/3) metabotropic glutamate receptor agonists LY379268 and LY389795 in persistent and inflammatory pain models after acute and repeated dosing. Neuropharmacology 49(Suppl 1), 206-218.

Karim, F., Wang, C. C., and Gereau, R. W. (2001). Metabotropic glutamate receptor subtypes 1 and 5 are activators of extracellular signal-regulated kinase signaling required for inflammatory pain in mice. J. Neurosci. 21,3771-3779.

Keywood, C., Wakefield, M., and Tack, J. (2009). A proof-of-concept study evaluating the effect of ADX10059, a metabotropic glutamate receptor-5 negative allosteric modulator, on acid exposure and symptoms in gastrooesophageal reflux disease. Gut 58, 1192-1199.

Laird, J. M., Martinez-Caro, L., GarciaNicas, E., and Cervero, F. (2001). A new model of visceral pain and referred hyperalgesia in the mouse. Pain 92, 335-342.

Lindstrom, E., Brusberg, M., Hughes, P.A., Martin, C. M., Brierley, S. M., Phillis, B. D., Martinsson, R., Abrahamsson, C., Larsson, H., Martinez, V., and Blackshaw, L. A. (2008). Involvement of metabotropic glutamate 5 receptor in visceral pain. Pain 137, 295-305.

Liu, M., and Kirchgessner, A. L. (2000). Agonist- and reflex-evoked internalization of metabotropic glutamate receptor 5 in enteric neurons. $J$. Neurosci. 20, 3200-3205.

Liu, Z., Chen, C. Y., and Bonham, A. C. (1998). Metabotropic glutamate receptors depress vagal and aortic baroreceptor signal transmission in the NTS. Am. J. Physiol. 275, H1682-H1694.

Marabese, I., de Novellis, V., Palazzo, E., Scafuro, M. A., Vita, D., Rossi, F., and Maione, S. (2007). Effects of (S)-3,4DCPG, an mGlu8 receptor agonist, on inflammatory and neuropathic pain in mice. Neuropharmacology 52 , 253-262.

Marshall,F.H.(2001).Heterodimerization of G-protein-coupled receptors in the CNS. Curr. Opin. Pharmacol. 1,40-44.

Martinez, V., Thakur, S., Mogil, J. S., Tache, Y., and Mayer,E. A. (1999). Differential effects of chemical and mechanical colonic irritation on behavioral pain response to intraperitoneal acetic acid in mice. Pain 81, 179-186.

Millan, M. J. (1999). The induction of pain: an integrative review. Prog. Neurobiol. 57, 1-164.

Neto, L. F., Schadrack, J., Berthele, A., Zieglgansberger, W., Tolle, T. R., and Castro-Lopes, J. M. (2000). Differential distribution of metabotropic glutamate receptor subtype mRNAs in the thalamus of the rat. Brain Res. 854, 93-105.

Neugebauer, V. (2002). Metabotropic glutamate receptors - important modulators of nociception and pain behavior. Pain 98, 1-8.

Neuhuber, W. L. (1987). Sensory vagal innervation of the rat esophagus and cardia: a light and electron microscopic anterograde tracing study. J. Auton. Nerv. Syst. 20, 243-255.
Page, A. J., Dorian, C. M., O’Donnell, T. A., Mattsson, J.P., and Blackshaw, L.A. (2004). The metabotropic glutamate receptor mGluR4 is required for normal visceral mechanotransduction. Neurogastroenterol. Motil. 16, 839.

Page, A. J., Young, R. L., Martin, C. M., Umaerus, M., O'Donnell, T, A., Cooper, N. J., Coldwell, J. R., Hulander M., Mattsson, J. P., Lehmann, A., and Blackshaw, L.A. (2005). Metabotropic glutamate receptors inhibit mechanosensitivity in vagal sensory neurons. Gastroenterology 128, 402-410.

Partosoedarso, E. R., Young, R. L., and Blackshaw, L. A. (2001). GABA(B) receptors on vagal afferent pathways: peripheral and central inhibition. Am. J. Physiol. 280, G658-G668.

Raab, M., and Neuhuber, W. L. (2003). Vesicular glutamate transporter 2 immunoreactivity in putative vagal mechanosensor terminals of mouse and rat esophagus: indication of a local effector function? Cell Tissue Res. 312 , 141-148.

Raab, M., and Neuhuber, W. L. (2004). Intraganglionic laminar endings and their relationships with neuronal and glial structures of myenteric ganglia in the esophagus of rat and mouse. Histochem. Cell Biol. 122, 445-459.

Rong, W., Hillsley, K., Davis, J. B., Hicks, G., Winchester, W. J., and Grundy, D. (2004). Jejunal afferent nerve sensitivity in wild-type and TRPV1 knockout mice. J. Physiol. (Lond.) $560,867-881$.

Schoepp, D. D., Jane, D. E., and Monn, J.A. (1999). Pharmacological agents acting at subtypes of metabotropic glutamate receptors. Neuropharmacology 38, 1431-1476.

Shapiro, R. E., and Miselis, R. R. (1985). The central organization of the vagus nerve innervating the stomach of the rat. J. Comp. Neurol. 238, 473-488.

Slattery, J. A., Page, A. J., Dorian, C., Brierley, S., and Blackshaw, L. A. (2006). Potentiation of vagal afferent mechanosensitivity by ionotropic and metabotropic glutamate receptors. $J$. Physiol. (Lond.), 577, 295-306.

Swanson, C. J., Bures, M., Johnson, M. P., Linden, A. M., Monn, J. A., and Schoepp, D. D. (2005). Metabotropic glutamate receptors as novel targets for anxiety and stress disorders. Nat. Rev Drug Discov. 4, 131-144.

Tan, L. L., Bornstein, J. C., and Anderson, C. R. (2009). Neurochemical and morphological phenotypes of vagal afferent neurons innervating the adult mouse jejunum. Neurogastroenterol. Motil. 21, 994-1001.

Tao, Y. X., Li, Y. Q., Zhao, Z. Q., and Johns, R. A. (2000). Synaptic relationship of the neurons containing a metabo- tropic glutamate receptor, MGluR5, with nociceptive primary afferent and GABAergic terminals in rat spinal superficial laminae. Brain Res. 875 , 138-143.

Valerio, A., Rizzonelli, P., Paterlini, M., Moretto, G., Knopfel, T., Kuhn, R., Memo, M., and Spano, P. (1997). mGluR5 metabotropic glutamate receptor distribution in rat and human spinal cord: a developmental study. Neurosci. Res. 28, 49-57.

Varty, G. B., Grilli, M., Forlani, A., Fredduzzi, S., Grzelak, M. E., Guthrie, D. H., Hodgson, R. A., Lu, S. X., Nicolussi, E., Pond, A. J., Parker, E. M., Hunter, J. C., Higgins, G. A., Reggiani, A., and Bertorelli, R. (2005). The antinociceptive and anxiolytic-like effects of the metabotropic glutamate receptor 5 (mGluR5) antagonists, MPEP and MTEP, and the mGluR1 antagonist, LY456236, in rodents: a comparison of efficacy and side-effect profiles. Psychopharmacology (Berl.) 179, 207-217.

Walker, K., Bowes, M., Panesar, M., Davis, A., Gentry, C., Kesingland, A., Gasparini, F., Spooren, W., Stoehr, N., Pagano, A., Flor, P. J., Vranesic, I., Lingenhoehl, K., Johnson, E. C., Varney, M., Urban, L., and Kuhn, R. (2001a). Metabotropic glutamate receptor subtype 5 (mGlu5) and nociceptive function. I. Selective blockade of mGlu5 receptors in models of acute, persistent and chronic pain. Neuropharmacology 40, 1-9.

Walker, K., Reeve, A., Bowes, M., Winter, J., Wotherspoon, G., Davis, A., Schmid, P., Gasparini, F., Kuhn, R., and Urban, L. (2001b). mGlu5 receptors and nociceptive function II. mGlu5 receptors functionally expressed on peripheral sensory neurones mediate inflammatory hyperalgesia. Neuropharmacology 40, 10-19.

Yamakura, T., and Shimoji, K. (1999). Subunit- and site-specific pharmacology of the NMDA receptor channel. Prog. Neurobiol. 59, 279-298.

Young, R. L., Cooper, N. J., and Blackshaw, L. A. (2008a). Anatomy and function of group III metabotropic glutamate receptors in gastric vagal pathways. Neuropharmacology 54, 965-975.

Young, R. L., Cooper, N. J., and Blackshaw, L. A. (2008b). Chemical coding and central projections of gastric vagal afferent neurons. Neurogastroenterol. Motil. 20, 708-718.

Young, R. L., Page, A. J., O’Donnell, T. A., Cooper, N. J., and Blackshaw, L. A. (2007). Peripheral versus central modulation of gastric vagal pathways by metabotropic glutamate receptor 5 . Am. J. Physiol. 292, G501-G511.

Zagorodnyuk, V., Chen, B., and Brookes, S. (2001). Intraganglionic laminar 
endings are mechano-transduction sites of vagal tension receptors in theguinea-pig stomach. J. Physiol. 534, 255-268.

Zagorodnyuk, V. P., and Brookes, S. J. (2000). Transduction sites of vagal mechanoreceptors in the guinea pig esophagus. J. Neurosci. 20, 6249-6255.

Zagorodnyuk, V. P., Chen, B. N., Costa, M., and Brookes, S. J. (2003). Mechanotransduction by intraganglionic laminar endings of vagal tension receptors in the guinea-pig oesophagus. J. Physiol. 553, 575-587.
Zhou, S., Komak, S., Du, J., and Carlton, S. M. (2001). Metabotropic glutamate lalpha receptors on peripheral primary afferent fibers: their role in nociception. Brain Res. 913, 18-26.

Zhu,C.Z.,Hsieh, G.,Ei-Kouhen,O.,Wilson, S. G., Mikusa, J. P., Hollingsworth, P. R., Chang, R., Moreland, R. B., Brioni, J., Decker, M. W., and Honore, P. (2005). Role of central and peripheral mGluR5 receptors in post-operative pain in rats. Pain 114, 195-202.

Zhu, C. Z., Wilson, S. G., Mikusa, J. P., Wismer, C. T., Gauvin, D. M., Lynch, J. J. III, Wade, C. L., Decker, M. W., and
Honore, P. (2004). Assessing the role of metabotropic glutamate receptor 5 in multiple nociceptive modalities. Eur. J. Pharmacol. 506, 107-118.

Conflict of Interest Statement: The authors declare that the research was conducted in the absence of any commercial or financial relationships that could be construed as a potential conflict of interest.

Received: 13 April 2010; accepted: 14 March 2011; published online: 24 March 2011.

Citation: Blackshaw LA, Page AJ and Young RL (2011) Metabotropic glu- tamate receptors as novel therapeutic targets on visceral sensory pathways. Front. Neurosci. 5:40. doi: 10.3389/ fnins.2011.00040

This article was submitted to Frontiers in Autonomic Neuroscience, a specialty of Frontiers in Neuroscience.

Copyright (C) 2011 Blackshaw, Page and Young. This is an open-access article subject to a non-exclusive license between the authors and Frontiers Media SA, which permits use, distribution and reproduction in other forums, provided the original authors and source are credited and other Frontiers conditions are complied with. 